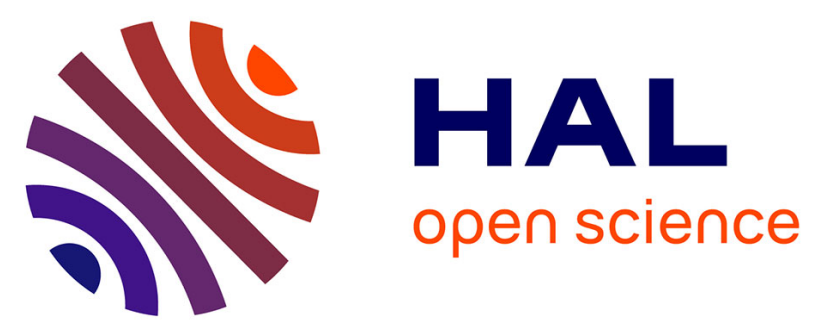

\title{
One-Pot Assembly of Unsymmetrical Biaryl Thioglycosides through Chemoselective Palladium-Catalyzed Three-Component Tandem Reaction
}

Sara Benmahdjoub, Nada Ibrahim, Belkacem Benmerad, Mouad Alami, Samir Messaoudi

\section{To cite this version:}

Sara Benmahdjoub, Nada Ibrahim, Belkacem Benmerad, Mouad Alami, Samir Messaoudi. One-Pot Assembly of Unsymmetrical Biaryl Thioglycosides through Chemoselective PalladiumCatalyzed Three-Component Tandem Reaction. Organic Letters, 2018, 20 (13), pp.4067-4071. 10.1021/acs.orglett.8b01624 . hal-02414163

\section{HAL Id: hal-02414163 https://hal.science/hal-02414163}

Submitted on 16 Dec 2019

HAL is a multi-disciplinary open access archive for the deposit and dissemination of scientific research documents, whether they are published or not. The documents may come from teaching and research institutions in France or abroad, or from public or private research centers.
L'archive ouverte pluridisciplinaire HAL, est destinée au dépôt et à la diffusion de documents scientifiques de niveau recherche, publiés ou non, émanant des établissements d'enseignement et de recherche français ou étrangers, des laboratoires publics ou privés. 


\title{
A One-Pot Assembly of Unsymmetrical Biaryl Thioglycosides Through Chemoselective Palladium-Catalyzed Three- Component Tandem Reaction
}

\author{
Sara Benmahdjoub, ${ }^{\mathrm{a}, \mathrm{b}}$ Nada Ibrahim, ${ }^{\mathrm{a}}$ Belkacem Benmerad, ${ }^{\mathrm{b}}$ Mouad Alami, ${ }^{\mathrm{a}, *}$ and Samir \\ Messaoudi $^{\mathrm{a}, *}$ \\ ${ }^{a}$ BioCIS, Univ. Paris-Sud, CNRS, University Paris-Saclay, Châtenay-Malabry, France \\ ${ }^{\mathrm{b}}$ Laboratoire de Physico-Chimie des Matériaux et Catalyse, Faculté des Sciences Exactes, Université de Bejaia, $06000 \mathrm{Be}-$ \\ jaia, Algeria
}

Supporting Information Placeholder

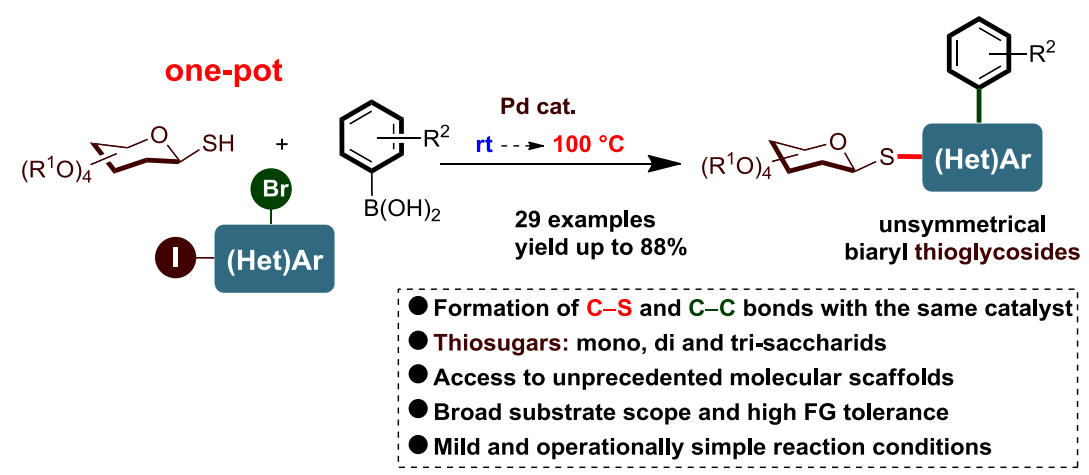

ABSTRACT: A range of unsymmetrical biaryls bearing thiosugars could be synthesized in a one-pot multicomponent
approach using one catalytic palladium system that permitted the $\mathrm{C}-\mathrm{S}$ and $\mathrm{C}-\mathrm{C}$ bonds forming. The reaction showed a
high selectivity and was applied to a broad variety of substrates giving access to novel glycosylated bi-aryl structures in
good yields.

Functionalized unsymmetrical biaryls are of great prevalence in Nature ${ }^{1}$ and are found in many important medicinal compounds (Telmizartan, Boscalid). In addition, they are used in materials chemistry as semiconductors ${ }^{2}$ or as ligands for asymmetric catalysis. ${ }^{3}$ Biaryl platforms bearing donor and acceptor moieties have important optical properties and have been studied for photolability as twophoton sensitive photoremovable protecting groups for biologically-active molecules delivery ${ }^{4}$. Interestingly, unsymmetrical biaryls functionalized with sugar groups are less reported in the literature. Several pharmacologically important biphenyl glycosides have been described (Figure 1). Lysilactone A is used in traditional Chinese folk medicine. ${ }^{5}$ Biphenylglycosides ${ }^{6} \mathbf{2}$ and 3 have significant antioxidant activity. ${ }^{7}$ Mannoside $\mathbf{4}$ is a highly efficient FimH antagonist ${ }^{8}$ used for the treatment of urinary tract infections (UTIs). Moreover, several diphenylmethyl- $\beta-C$ glycosides such as dapagliflozin have been synthesized as potent inhibitors of SGLT2. ${ }^{9}$

Usually, unsymmetrical biaryls are prepared from haloarenes or triflates, ${ }^{10}$ either by palladium ${ }^{11}$ or by nickel ${ }^{12}$ catalyzed cross couplings. They can also be obtained by coupling of two aryls with hypervalent silicon reagents, ${ }^{13}$ or by $\mathrm{C}-\mathrm{H}$ bond activation. ${ }^{14}$ However, few examples of "one pot $^{115}$ sequential procedures have been reported in the literature. Among these are the Diels-Alder cycloaddition or the reaction of arylhalides with bis(pinacolato)diboron followed by coupling with

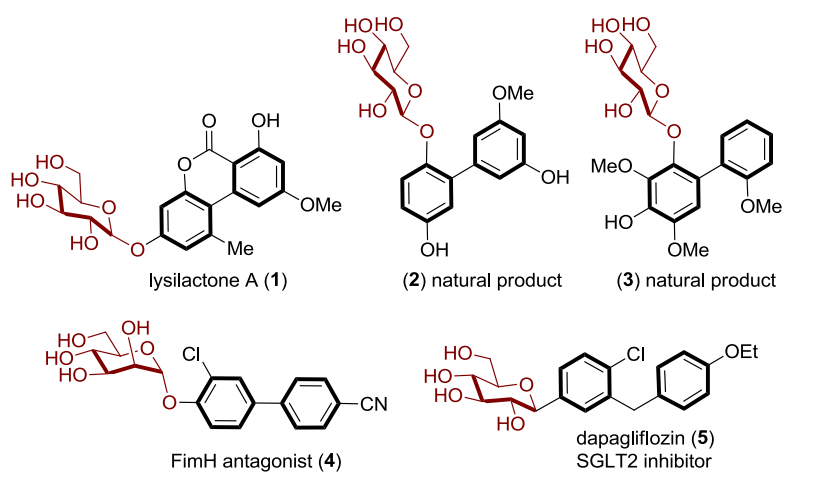

Figure 1. Example of Natural and Synthetic Biaryl Glycosides another arylhalide. ${ }^{16}$ Nevertheless, structures of biaryls bearing thiosugars and synthetic methods leading to their formation are non-existent. ${ }^{17}$ Thiosugars can be used as 
sugar surrogates; therefore, their introduction into biaryls is highly relevant since biarylthioglycosides can be investigated as mimetics of biologically relevant $O$-glycosides. $S$ Glycosides are much more stable than $O$-glycosides to both chemical and enzymatic degradation and have been utilized as enzyme inhibitors in various biochemical studies. ${ }^{18}$ Owing to the significant importance of biphenylglycosides, there is a strong impetus to discover new chemical transformations for their efficient synthesis and functionalization.

As part of our continuing effort to provide the chemistry community with more efficient ways to produce high value thioglycosides, ${ }^{19}$ we became interested in extending our recently disclosed $\mathrm{PdG}_{3}$-catalyzed arylation of thiosugars at room temperature with aryliodides ${ }^{20}$ into a tandem multicomponent reaction (MCR) involving iodobromoarenes, thiosugars and arylboronic acids. The procedure consists on using one Pd-catalyst which, under the same catalytic cycle, will promote the catalysis of two individual steps; $i$ ) the first is the selective creation of the $\mathrm{S}-\mathrm{C}$ bond between $\beta$-thiosugars and dihalogenated arenes (iodo-bromoarenes); ii) the second is based on C-C bond formation between the monohalogenated thioglycoside intermediate and diverse arylboronic acids. We could assume that in the presence of a nonselective catalyst, the reaction could statistically generate a complex mixture of up to three possible products (Table 1 ). In this regard, we wished to take advantages of the selectivity of oxidative addition of a C-I bond to Pd (o) species followed by the insertion of a thiol function at room temperature and to then perform a Suzuki-Miyaura coupling reaction at the remaining $\mathrm{C}-\mathrm{Br}$ bond. We have focused our objective to find one catalytic system that will be highly selective toward the formation of the desired biarylglycoside product 4a. From a synthetic viewpoint, this procedure would offers the shortest and the most efficient route to biarylglycosides for the purpose of medicinal chemistry screening program. Herein, we report our success in the development of such protocol.

Initial selectivity tests were performed using $\mathrm{PdG}_{3}$ XantPhos (10 mol \%) as a catalyst, which was reported previously by our group to be effective for the arylation of thiosugars. ${ }^{20}$ The selectivity was first examined in a model three-component reaction that utilized the tetraacetylated $\beta$-thiogalactose 1a (1 equiv), 1-bromo-3-iodobenzene 2 a (1 equiv) and (4-methoxyphenylboronic acid 3a (1.5 equiv) (Table 1). Gratifyingly, by running the reaction in wet THF for $15 \mathrm{~min}$ at room temperature and $3 \mathrm{~h}$ at $100{ }^{\circ} \mathrm{C}$ using a combination of two bases $\mathrm{NEt}_{3}$ and $\mathrm{K}_{2} \mathrm{CO}_{3}$ (4 equiv), we were able to achieve a complete selectivity toward the $\mathrm{C}-\mathrm{I}$ and $\mathrm{C}-\mathrm{Br}$ bonds. Under these conditions, compound $4 \mathbf{a}$ was isolated in $48 \%$ yield without any side products (Table 1, entry 1). Then we attempted to omit $\mathrm{NEt}_{3}$ and to our satisfaction, by adding $\mathrm{K}_{2} \mathrm{CO}_{3}$ (4 equiv) and heating overnight at $80^{\circ} \mathrm{C}, 4 \mathrm{a}$ was obtained in $55 \%$ yield (Table 1, entry 2). Since the latter conditions were superior, we settled on these, using $\mathrm{K}_{2} \mathrm{CO}_{3}$ as a base. Stirring the mixture at $100{ }^{\circ} \mathrm{C}$ in the presence of two equivalents of arylboronic for $12 \mathrm{~h}$, decreased the yield to $42 \%$ and led to by-product formation (Table 1, entry 3). Surprisingly, by shortening the reaction time from $12 \mathrm{~h}$ to $5 \mathrm{~h}$, the biphenyl $\beta$-thioglycoside $\left(J_{1,2}=9.9 \mathrm{~Hz}\right)$ 4a was isolated in $83 \%$ yield when 1.2 equiv of thiogalactose 1a were used (Table 1, entry 4). Fortunately, reducing the catalyst loading to $5 \mathrm{~mol} \%$ gave $\mathbf{4 a}$ in a similar yield (82\%, Table 1, entry 5$)$. A second part of this optimization focused upon investigating the feasibility of the reaction at the same temperature $\left(100{ }^{\circ} \mathrm{C}\right)$. Simple mixing of the three components 1a (1.2 equiv), 2 a (1 equiv) and $3 \mathbf{a}$ ( 2 equiv) at $100{ }^{\circ} \mathrm{C}$ furnished product $4 \mathbf{a}$ in a good $81 \%$ yield and with a perfect control of the anomeric configuration $\left(J_{1,2}=9.9 \mathrm{~Hz}\right)$. One can be noted that in all cases, the monohalogenated thioglycoside intermediate has never been observed during the process.

Motivated by these exciting results, we subsequently investigated the substrate scope for this tandem catalytic process by systematically varying the boronic acids 3 , iodobromoarenes 2a-e and the thiosugar substrates 1a-g (Scheme 1).

Table 1 Optimization of the Coupling Reaction of Tetraacetylated $\beta$ thiogalactose 1a, 1-Bromo-3-iodobenzene 2a and (4Methoxyphenylboronic acid $\mathbf{3 a}^{a}$

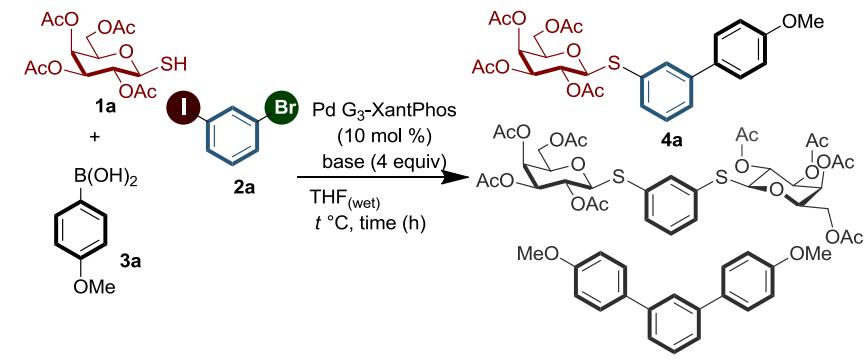

$\begin{array}{cccclc}\text { entry } & \text { base } & t\left({ }^{\circ} \mathrm{C}\right) & \text { time }(\mathrm{h}) & \mathbf{4 a}(\%)^{b} & \mathbf{5 a / 6 a ( \% )} \\ 1 & \mathrm{Et}_{3} \mathrm{~N} / \mathrm{K}_{2} \mathrm{CO}_{3} & \text { rt then 100 } & 3 & 48 & \text { o/o } \\ 2 & \mathrm{~K}_{2} \mathrm{CO}_{3} & \text { rt then 8o } & 12 & 55 & \text { o/o } \\ 3 & \mathrm{~K}_{2} \mathrm{CO}_{3} & \text { rt then 100 } & 12 & 42 & \text { o/o } \\ 4 & \mathrm{~K}_{2} \mathrm{CO}_{3} & \text { rt then 10o } & 5 & 83 & \text { o/o } \\ 5 & \mathrm{~K}_{2} \mathrm{CO}_{3} & \text { rt then 100 } & 5 & 82^{c, d} & \text { o/o } \\ 6 & \mathrm{~K}_{2} \mathrm{CO}_{3} & 100 & 5 & 81^{c, d, e} & \text { o/o }\end{array}$

${ }^{a}$ A sealable tube was charged with thiosugar 1a (1 equiv), 1-bromo-3iodobenzene 2a (1 equiv), 4-methoxyphenylboronic acid 3a (1.5 equiv), PdG3 XantPhos (10 mol \%), base (4 equiv) in THF(wet) (0.22 M) at $\mathrm{rt}(15 \mathrm{~min})$ then $5 \mathrm{~h}$ at $100{ }^{\circ} \mathrm{C}$. ${ }^{b}$ Yield of isolated product. ${ }^{c} 5$ mol $\%$ of PdG3 XantPhos. ${ }^{d} 1.2$ equiv of 1 a were used. ${ }^{e}$ The reaction was performed at the same temperature $\left(100{ }^{\circ} \mathrm{C}\right)$.

Gratifyingly, all the tandem S- and C-arylations proceeded cleanly and selectively in good yields. As illustrated in Scheme 1, a variety of electron-rich and electron-deficient, para and meta substituted arylboronic acids effectively underwent reaction with 1-bromo-3-iodobenzene $\mathbf{2 a}$ and tetra- $O$-acetylated 1 -thio- $\beta$-D-glucopyranose $\mathbf{1 a}$ in yields up to $80 \%$ (products $4 \mathbf{a}-\mathbf{f}, \mathbf{4} \mathbf{h}$, and $\mathbf{4 i - k}$ ). In addition, the sterically demanding ortho substitution pattern engaged in the tandem coupling reaction of $\mathbf{1 a}$, furnishing compounds $4 \mathrm{~g}$ and $4 \mathbf{l}, \mathrm{m}$ having an ortho substituent group. Interestingly, heteroarene boronic acids such as pyridyl-4ylboronic acid and quinoleinyl-6-boronic acid were good substrates in this reaction (compounds $\mathbf{4 n}, \mathbf{o}$ ). In addition this tandem process was successfully expanded to the coupling of styryl boronic acid providing thioglycosylated stilbene $\mathbf{4 P}$ in an acceptable $56 \%$ yield (Scheme 1 ).

The reaction of unsubstituted para-iodo-bromobenzene 2b with thiogalactose $\mathbf{1 a}$ and boronic acids resulted also in selective formation of biphenyl para- $\beta$-thioglycoside $\mathbf{4 q}$ in a good yield, while the ortho-dihalogenated substrate $\mathbf{2 c}$ gave only a moderate yield of $4 \mathbf{r}$ ( $32 \%$ yield), probably due to steric hindrance. The same product was obtained in 
$68 \%$ yield over two steps when $\mathrm{PdCl}_{2}$.dppf was used as the catalyst for the Suzuki-Miyaura coupling. Interestingly, the tri-halogenated substrate $2 \mathbf{d}$ was used successfully in this MCR coupling leading selectively to thioglycoside 45 in $51 \%$ yield without affecting the remaining $\mathrm{C}-\mathrm{Cl}$ bond.

Finally, extending this method to dihalopyridine-based substrate where the catalyst could be deactivated via Pdpyridine coordination, also proved to be successful. Thus, 3-bromo-5-iodopyridine $\mathbf{2 e}$ was a good partner with $\mathbf{1 a}$ and 3a under our optimized conditions, furnishing the desired product 4 t in $54 \%$ yield.

Of note that in all the studied cases, compounds $4 \mathbf{a - t}$ were isolated as single anomers, clearly indicating that the tandem process is stereoretentive with report to the anomeric configuration of the sugar moiety.

Scheme 1 Scope of One-Pot Boronic Acids 2 Coupling with Thiogalactose 1a and Iodo-bromoarenes 3a-d

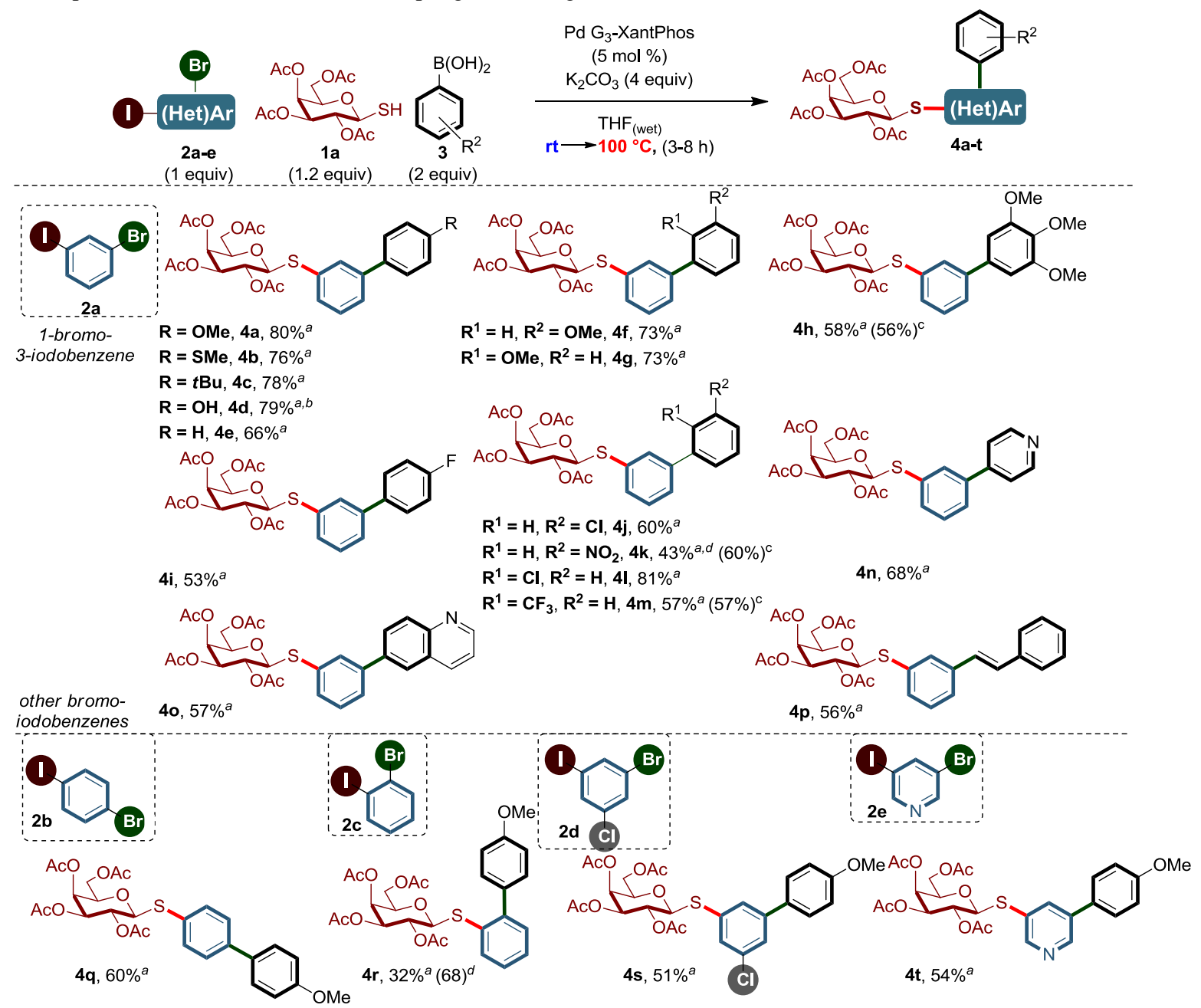

Reaction conditions: Thiosugar 1a (0.6 mmol), bromo-iodo-benzenes $\mathbf{2 a}-\mathbf{d}$ ( $0.5 \mathrm{mmol})$, boronic acid 3 (2 equiv), PdG3 XantPhos ( $5 \mathrm{~mol} \%), \mathrm{K}_{2} \mathrm{CO}_{3}$ (4 equiv) in THF(wet) $(0.22 \mathrm{M})$ at $\mathrm{rt}(15 \mathrm{~min})$ then $5 \mathrm{~h}$ at $100{ }^{\circ} \mathrm{C}$. ${ }^{a}$ Yield of isolated product.

${ }^{b}$ Reaction performed in a sequential way by isolating the intermediate. ${ }^{c}$ One-pot reaction performed at $100{ }^{\circ} \mathrm{C}$ for $5 \mathrm{~h}$.

${ }^{d}$ Yield of the isolated product $4 \mathbf{r}$ when the reaction of the 2-bromothiogalactosylbenzene intermediate and $3 \mathbf{a}$ was performed in the presence of $\mathrm{PdCl}_{2} \cdot \mathrm{dppf}$ as the catalyst (see Supporting Information).

Regarding the sugar partners, this coupling reaction tolerates a large variety of glycosylthiols 1a-g (Scheme 2): $\mathrm{O}$ acetylated 1-thio- $\beta$-D-galactopyranose 1a, $O$-acetylated 1thio- $\beta$-D-glycopyranose $\mathbf{1 b}, O$-benzoylated 1-thio- $\beta$-Dglucopyranose ic and $O$-acetylated $N$-Ac-1-thio- $\beta$-Dglucopyranose $\mathbf{1 d}$ all coupled with the dihalobenzenes $\mathbf{2 a - b}$ to give biphenylthioglycosides $\mathbf{5}^{\mathbf{a}-\mathbf{e}}$ in respectable yields. Importantly, this procedure is not limited to only protected $\beta$-glycosyl thiols, but it also worked successfully with unprotected 1-thioglucose 1e without any loss of reactivity. In this cases products $\mathbf{5 f , g}$ were obtained in $63 \%$ and $50 \%$ yields, respectively. Moreover, the reaction is not limited to monosaccharides, but can be applied to more complex di- and trisaccharide derivatives. Thus, 1-thio- $\beta$-Dcellobiose if and 1-thio- $\beta$-D-maltotriose $\mathbf{1 g}$ were efficiently reacted with 1-bromo-3-iodobenzene $\mathbf{2 a}$ to give original biphenyl structures $\mathbf{5 h} \mathbf{h}$ featuring di-and trisaccharides. Importantly, the stereochemistry of the $\beta-1,4-O$-glycosidic bond in the disaccharides $\mathbf{5 h}$ and the $\alpha-1,4$ ' in $\beta$ trisaccharide $\mathbf{5} \mathbf{i}$ remained intact.

In summary, we have developed an efficient and versatile protocol for the one-pot multicomponent preparation of biphenylthioglycosides. The method tolerates a wide range of functional groups and a variety of protected and unprotected glycosylthiols could be used. We expect this simple 
and general method to be of broad utility for the synthesis and development of new medicinal agents.

\section{ASSOCIATED CONTENT}

\section{Supporting Information}

The Supporting Information is available free of charge on the ACS Publications website.

Experimental procedures, spectroscopic data and NMR spectra of new compounds.

\section{AUTHOR INFORMATION}

Corresponding Author

* samir.messaoudi@u-psud.fr, mouad.alami@u-psud.fr

\section{Author Contributions}

The manuscript was written through contributions of all authors. / All authors have given approval to the final version of the manuscript.

Scheme 2 Scope of One-Pot Thiosugars 1b-g Coupling With Boronic Acid 2a Iodo-bromoarenes 3a-d

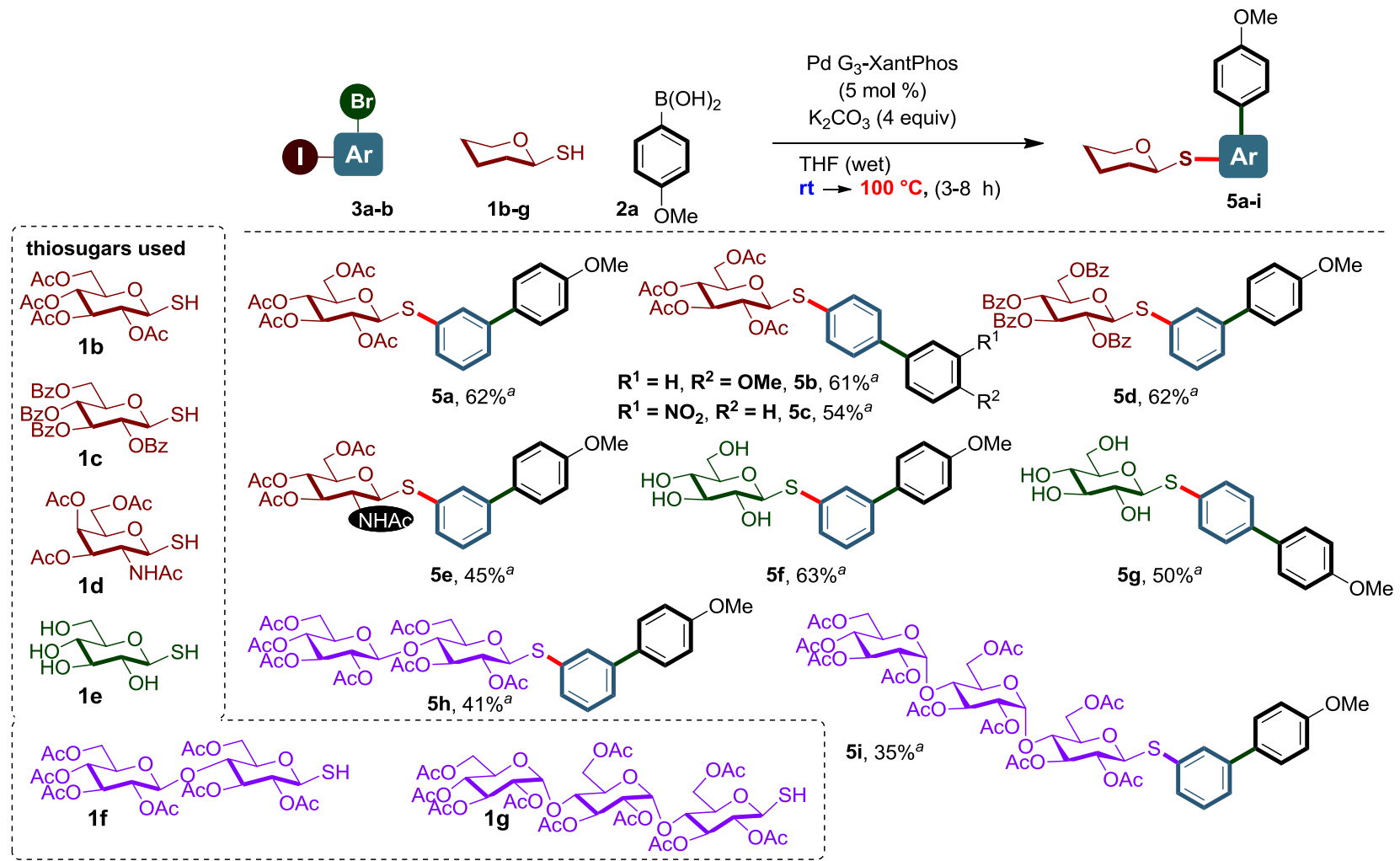

Reaction conditions: Thiosugar 1 a $(0.6 \mathrm{mmol})$, bromo-iodo-benzene $\mathbf{2 a}-\mathbf{d}$ ( $0.5 \mathrm{mmol})$, boronic acid 3 (2 equiv), PdG3 XantPhos ( $5 \mathrm{~mol} \%), \mathrm{K}_{2} \mathrm{CO}_{3}$ (4 equiv) in THF(wet) $(0.22 \mathrm{M})$ at $\mathrm{rt}(15 \mathrm{~min})$ then $5 \mathrm{~h}$ at $100{ }^{\circ} \mathrm{C}$. ${ }^{a}$ Yield of isolated product.

\section{ACKNOWLEDGMENTS}

Authors acknowledge support of this project by CNRS, University Paris-Sud, ANR (ANR-15-CE29- 0002), and by la Ligue Contre le Cancer through an Equipe Labellisée 2014 grant. We also thank the Algerian Ministry of Education and Research for a fellowship (PNE) to Sara Benmahdjoub. Our laboratory is a member of the Laboratory of Excellence LERMIT supported by a grant (ANR-10-LABX-33)

\section{REFERENCES}

(1) (a) Torssell, K. G. B. Natural Product Chemistry. John Wiley \& Sons; Chichester, 1983; (b) Manitto, P. Biosynthesis of Natural Products. John Wiley \& Sons; Chichester, 1981.

(2) Shih, H. T.; Lin, C. H.; Shih, H. H.; Cheng, C. H. High-Performance Blue Electroluminescent Devices Based on a Biaryl. Adv. Mater. 2002, 14, 1409.

(3) Kumarasamy, E.; Raghunathan, R.; Sibi, M. P.; Sivaguru, J. Nonbiaryl and Heterobiaryl Atropisomers: Molecular Templates with 
Promise for Atropselective Chemical Transformations. Chem. Rev. 2015, $115,11239$.

(4) (a) Aujard, I.; Benbrahim, C.; Gouget, M.; Ruel, O.; Baudin, J.B.; Neveu, P.; Jullien, L. o-Nitrobenzyl Photolabile Protecting Groups with Red-Shifted Absorption: Syntheses and Uncaging Cross-Sections for One- and Two-Photon Excitation; Chem. Eur. J. 2006, 12, 6865. (b) Specht, A.; Bolze, F.; Donato, L.; Herbivo, C.; Charon, S.; Warther, D.; Gug, S.; Nicoud, J.-F.; Goeldner, M. The donor-acceptor biphenyl platform: a versatile chromophore for the engineering of highly efficient two-photon sensitive photoremovable protecting groups. Photochem. Photobiol. Sci. 2012, 11, 578 .

(5) Liang D.; Luo H.; Liu Y.-F.; Hao Z.-Y.; Wang Y.; Zhang C.-L.; Zhang Q.-J.; Chen R.-Y.; Yu D.-Q. Lysilactones A-C, three $6 \mathrm{H}$ dibenzo[b,d]pyran-6-one glycosides from Lysimachia clethroides, total synthesis of Lysilactone A. Tetrahedron 2013, 69, 2093.

(6) (a) Dai, Y.; Zhou, G. X.; Kurihara, H.; Ye, W.; Yao, X. S. Biphenyl glycosides from the fruit of Pyracantha fortuneana. J. Nat. Prod. 2006, 69, 1022. (b) Zou, J.; Jin, D.; Chen, W.; Wang, J.; Liu, Q.; Zhu, X.;.Zhao W. Selective Cyclooxygenase-2 Inhibitors from Calophyllum membranaceum. J. Nat. Prod. 2005, 68, 1514.

(7) Jung, M. J.; Kang, S. S.; Jung, Y. J.; Choi, J. S. Phenolic Glycosides from the Stem Bark of Albizzia julibrissin. Chem. Pharm. Bull. 2004, 52, 1501.

(8) (a) Kleeb S.; Pang L.; Mayer K.; Eris D.; Sigl A.; Preston R. C.; Zihlmann P.; Sharpe T.; Jakob R. P.; Abgottspon D., Hutter A. S.; Scharenberg M.; Jiang X.; Navarra G., Rabbani S., Smiesko M.; Lüdin N.; Bezençon J.; Schwardt O.; Maier T.; Ernst B. FimH antagonists: bioisosteres to improve the in vitro and in vivo PK/PD profile. J. Med. Chem., 2015, 58, 2221 (b) Kleeb S.; Jiang X.; Frei P.; Sigl A.; Bezençon J.; Bamberger K.; Schwardt O.; Ernst B. FimH Antagonists: Phosphate Prodrugs Improve Oral Bioavailability. J. Med. Chem., 2016, 59, 3163.

(9) Chao, E. C.; Henry, R. R. SGLT2 inhibition--a novel strategy for diabetes treatment. Nat. Rev. (Drug Discov) 2010, 9, 551 and references cited therein

(10) (a) Hassan, J.; Sévignon, M.; Gozzi, C.; Schulz, E.; Lemaire, M. Aryl-aryl bond formation one century after the discovery of the Ullmann reaction. Chem. Rev. 2002, 102, 1359. (b) Bringmann, G.; Walter, R.; Weirich, R. The Directed Synthesis of Biaryl Compounds: Modern Concepts and Strategies.Angew. Chem. Int. Ed. 1990, 29, 977.

(11) (a) Hassan, J.; Hathroubi, C.; Gozzi, C.; Lemaire, M. Synthesis of unsymmetrical biaryls via palladium-catalyzed coupling reaction of aryl halides. Tetrahedron Lett. 20oo, 41, 8791. (b) Wang, L.; Lu, W. Preparation of Unsymmetrical Biaryls by Pd(II)-Catalyzed Cross-Coupling of Aryl Iodides. Org. Lett. 2oo9, 11, 1079 .

(12) (a) Hornillos, V.; Giannerini, M.; Vila, C.; Fañanás-Mastral, M.; Feringa, B. L. Catalytic Direct Cross-Coupling of Organolithium Compounds with Aryl Chlorides. Org. Lett. 2013, 15, 5114. (b) Malineni, J.; Jezorek, R. L.; Zhang, N.; Percec, V. An Indefinitely Air-Stable $\sigma$-NiII Precatalyst for Quantitative CrossCoupling of Unreactive Aryl Halides and Mesylates with Aryl Neopentylglycolboronates. Synthesis 2016, 48, 2795.

(13) Mowery, M. E.; DeShong, P. Synthesis of Unsymmetrical Biaryls by Palladium-Catalyzed Cross Coupling Reactions of Arenes with Tetrabutylammonium Triphenyldifluorosilicate, a Hypervalent Silicon Reagen. J. Org. Chem. 1999, 64, 3266.

(14) Li, W.; Xu, Z.; Sun, P.; Jiang, X.; Fang, M. Synthesis of Biphenyl-2-carbonitrile Derivatives via a Palladium-Catalyzed sp2 $\mathrm{C}-\mathrm{H}$ Bond Activation Using Cyano as a Directing Group. Org; Lett. 2011, 13, 1286.
(15) (a) Zhao W.; Chen F.E. One-pot Synthesis and its Practical Application in Pharmaceutical Industry. Curr. Org. Synth. 2012, 9, 873. (b) Xu, P.-F.; Wang, W. Wiley: Hoboken, NJ 2014. (c) Vlaar, T.; Ruijter, E.; Orru, R. V. A. Adv. Synth. Cat. 2011, 353, 809 .

(16) (a) Miura, M.; Koike, T.; Ishihara, T.; Sakamoto, S.; Okada, M.; Ohta, M.; Tsukamoto, S. i. One-Pot Preparation of Unsymmetrical Biaryls via Suzuki Cross-Coupling Reaction of Aryl Halide using Phase-Transfer Catalyst in a Biphasic Solvent System. Synth. Commun. 2007, 37, 667. (b) Giroux, A.; Han, Y.; Prasit, P. One pot biaryl synthesis via in situ boronate formation. Tetrahedron. Lett. 1997, 38, 3841. (c) Molander, G. A.; Trice, S. L. J.; Dreher, S. D. Palladium-Catalyzed, Direct Boronic Acid Synthesis from Aryl Chlorides: A Simplified Route to Diverse Boronate Ester Derivatives. J. Am. Chem. Soc. 2010, 132, 17701. (d) Liu, Y.; Lu, K.; Dai, M.; Wang, K.; Wu, W.; Chen, J.; Quan, J.; Yang, Z. An Efficient One-Pot Asymmetric Synthesis of Biaryl Compounds via Diels-Alder/Retro-Diels-Alder Cascade Reactions. Org. Lett. 2007, 9, 805 .

(17) Al-Shuaeeb R. A. A.; Dejean C.; Alami M.; Messaoudi S. Controllable Activation of Pd-G3 Palladacycle Precatalyst in the Presence of Thiosugars: Rapid Access to 1-Aminobiphenyl Thioglycoside Atropoisomers at Room Temperature. Chem. Asian J. 2017, 12, 3114 .

(18) a) Rye C. S.; Withers S. G. The synthesis of a novel thiolinked disaccharide of chondroitin as a potential inhibitor of polysaccharide lyases. Carbohydr. Res. 2004, 339, 699. (b) Metaferia B. B.; Fetterolf B. J.; Shazadul-Hussan S.; Moravec M.; Smith J. A.; Ray S.; Gutierrez-Lugo M.-T.; Bewley C. A. Synthesis of Natural Product-Inspired Inhibitors of Mycobacterium tuberculosis Mycothiol-Associated Enzymes: The First Inhibitors of GlcNAc-Ins Deacetylase. J. Med. Chem. 2007, 50, 6326. (c) Castaneda F.; Burse A.; Boland W.; Kinne R. K.-H. Thioglycosides as inhibitors of hSGLT1 and hSGLT2: Potential therapeutic agents for the control of hyperglycemia in diabetes. Int. J. Med. Sci. 2007, 4, 131.

(19) (a) Brachet, E.; Brion, J.-D.; Messaoudi, S.; Alami, M. Stereoselective Palladium-Catalyzed Alkenylation and Alkynylation of Thioglycosides. Adv. Synth. Catal. 2013, 355, 2627. (b) Bruneau, A.; Brion, J.-D.; Alami, M.; Messaoudi, S. Stereoselective copper-catalyzed Chan-Lam-Evans $N$-arylation of glucosamines with arylboronic acids at room temperature. Chem. Commun. 2013, 49, 8359. (c) Brachet, E.; Brion, J.-D.; Alami, M.; Messaoudi, S. Nickel-Catalyzed Arylation, Alkenylation, and Alkynylation of Unprotected Thioglycosides at Room Temperature. Chem. Eur. J. 2013, 19, 15276. (d) Chabrier, A.; Bruneau, A.; Benmahdjoub, S.; Benmerad, B.; Belaid, S.; Brion, J.-D.; Alami, M.; Messaoudi, S. Stereoretentive Copper-Catalyzed Directed Thioglycosylation of $\mathrm{C}\left(\mathrm{sp}^{2}\right)-\mathrm{H}$ Bonds of Benzamides. Chem. Eur. J. 2016, 22, 15006. (e) Probst, N.; Grelier, G.; Ghermani, N.; Gandon, V.; Alami, M.; Messaoudi, S. Intramolecular Pd-Catalyzed Anomeric $\mathrm{C}\left(\mathrm{sp}^{3}\right)$-H Activation of Glycosyl Carboxamides. Org. Lett. 2017, 19, 5038. (f) AL-Shuaeeb, R. A. A.; Montoir, D.; Alami, M.; Messaoudi, S. J. Org. Chem. Synthesis of $(1 \rightarrow 2)$-S-Linked Saccharides and S-Linked Glycoconjugates via a Palladium-G3-XantPhos Precatalyst Catalysis. 2017, 82, 6720. (g) Probst, N.; Lartia, R.; Théry, O.; Alami, M.; Defrancq, E.; Messaoudi, S. Efficient Buchwald-HartwigMigita Cross-Coupling for DNA Thioglycoconjugation.Chem. Eur. J. 2018, 24, 1795.

(20) Bruneau, A.; Roche, M.; Hamze, A.; Brion, J.-D.; Alami, M.; Messaoudi, S. Stereoretentive Palladium-Catalyzed Arylation, Alkenylation, and Alkynylation of 1-Thiosugars and Thiols Using Aminobiphenyl Palladacycle Precatalyst at Room Temperature. Chem. Eur. J. 2015, 21, 8375 . 